\title{
How Much Fossil Fuel Is in the Earth?
}

\author{
Pier Paolo Prosini \\ Department of Energy Technologies, ENEA Italian National Agency for New Technologies, Energy and Sustainable Economic \\ Development, Santa Maria di Galeria, Rome, Italy \\ Email: pierpaolo.prosini@enea.it
}

How to cite this paper: Prosini, P. P. (2019). How Much Fossil Fuel Is in the Earth? Journal of Geoscience and Environment Protection, 7, 61-68.

https://doi.org/10.4236/gep.2019.75007

Received: March 11, 2019

Accepted: May 18, 2019

Published: May 21, 2019

Copyright $\odot 2019$ by author(s) and Scientific Research Publishing Inc. This work is licensed under the Creative Commons Attribution International License (CC BY 4.0).

http://creativecommons.org/licenses/by/4.0/

\begin{abstract}
In this work, by using an indirect method based on the correspondence between the amount of oxygen in the atmosphere and the quantity of fossil fuel in the Earth, the resources of fossil fuels were evaluated to be about $1.9 \times 10^{16}$ ton. Unluckily, only a small part of these fuels is easily accessible. Nevertheless, their quantity is so high that it is reasonable to assume that fossil fuels will continue to dominate the global energy scene for several years. The extensive use of fossil fuels alters the ratio between oxygen and carbon dioxide in the atmosphere. The effects of this change are however so slow that they become important only on the geological time scale.
\end{abstract}

\section{Keywords}

Fossil Fuels, Oxygen Production, Consumption Rate, Carbon Dioxide, Atmosphere

\section{Introduction}

The estimation of fossil fuels resources is one of the most controversial and important of all forecasting activities (Sterman \& Richardson 1985, Abas et al. 2015). Earth has a finite reserve of fossil fuels and oil, coal and natural gas are the main ones. And although we know they are finite, we don't really know how long they will last. To evaluate how long each fossil resource can be extracted at the present rate before the same is depleted, it is necessary to divide the total reserves of each fossil fuel with its rate of consumption (see Table 1). Although this is the easiest way to estimate how long each fossil fuel will last, there are some issues with this evaluation that must be taken into consideration in order to get an accurate projection. The principal point is the difficulty to correctly evaluate the total reserves of fossil fuels present into the deposit. The main estimation methods are based on the evaluation of physical variables of the field to 
Table 1. Latest estimates of global fossil fuel resources and reserves in million ton equivalent, as of January 2013.

\begin{tabular}{cccccc}
\hline Fossil fuel & $\begin{array}{c}\text { Production } \\
(\mathrm{P})\end{array}$ & $\begin{array}{c}\text { Reserve } \\
(\mathrm{R} 1)\end{array}$ & $\begin{array}{c}\mathrm{R} 1 / \mathrm{P} \\
(\text { years })\end{array}$ & $\begin{array}{c}\text { Resources } \\
(\mathrm{R} 2)\end{array}$ & $\begin{array}{c}\mathrm{R} 2 / \mathrm{P} \\
\text { (years) }\end{array}$ \\
\hline Crude oil & 4348 & 224,017 & 52 & 457,890 & 105 \\
Wet natural gas & 3160 & 174,293 & 55 & 583,152 & 1845 \\
Coal & 4784 & 597,382 & 125 & $13,394,221$ & 2799 \\
Hard coal & 4427 & 503,063 & 114 & $11,915,785$ & 2691 \\
Lignite & 357 & 94,319 & 264 & $1,478,436$ & 412 \\
\hline
\end{tabular}

Source: http://energy-ecology.blogspot.it/2013/06/latest-estimation-of-global-fossil-fuel.html.

be exploited. For example the method of the balance of the material puts in relation the volume of oil or gas produced in the history of the reservoir and the pressure changes observed in the same, the method of decline curves uses the data related to the historical production curve to estimate future production, while the volumetric methods seek to determine the quantity of fuel estimating the real dimensions of the reservoir. All these methods are very important from an economic point of view but do not give information on the total amount of fuel present within the Earth. This paper will try to give estimation about the total amount of fossil fuel present in the Earth, regardless of the nature of the fuel. To do that it is necessary to start from very far away, that is, since the Earth was originated about 4.5 billion years ago. Starting from the consideration that the primordial atmosphere did not contain oxygen, the work estimates how much oxygen has been produced over time. The consideration that for each mole of oxygen produced must match a mole of carbon on the earth, allowing us to estimate the amount of existing carbon. The work concludes by making some considerations on the speed with which we are burning these energy resources.

\section{Variation of the Atmosphere with Time}

\subsection{The Primitive Atmosphere}

The early Earth had to be very different from today, hot and inhospitable. This was due to the primordial heat of formation and for the continuous decay of radioactive elements that produce heat. The consequences were that the Earth had a semi-solid surface, was suffering from a constant volcanic activity and on it the water was absent in the liquid state (Yang et al. 2014). The first atmosphere was to be similar to that found in the universe, formed of rarefied gases, mainly hydrogen and helium. Following cooling, after many millions of years, the primordial heat was dissipated into the space. This allowed the water to condense and then plunging to the Earth as rain. The rains allowed the Earth's crust to harden and water to stagnate on its surface. The presence of water was crucial to achieve a favorable situation for the origin of life, which appears on the Earth about 4 
billion years ago. The primordial atmosphere had to be very different from today. The current atmosphere is formed mainly of nitrogen (about $80 \%$ by volume). It has no clearly defined boundaries: it simply dissipates into space. The dense portion of the atmosphere (which contains $97 \%$ of the total gas) falls within $30 \mathrm{~km}$ from the Earth's surface, occupying about the same thickness of the continental crust. As previously mentioned, the primordial atmosphere had to be very thin and probably formed by hydrogen and helium. Today these gases in the atmosphere are rare, but probably at the time that the Earth was formed, its atmosphere was not to be dissimilar to that of the universe. These gases were later lost in space because Earth's gravity was not enough to hold them.

\subsection{The Second Atmosphere}

At that time the Earth was not to have a center differentiated from the crust. The lack of an outer crust with a center fluid determined the absence of an electromagnetic field, with consequent absence of the Van Allen belts. The Van Allen belts are important to life on Earth as deflect the solar wind and cancel that part of the high-energy radiation that is not compatible with the development of life forms. The Van Allen belts are regions rich in high-energy particles, mainly protons and electrons, kept imprisoned by the Earth's magnetic field at a fixed distance from the planet. The bands of fast particles trapped around the Earth can be divided into two zones. An inner band, properly called Van Allen belt, in honor of its discoverer James Alfred Van Allen (Van Allen et al. 1958), located about $6300 \mathrm{~km}$ from the Earth and consisting predominantly of high-energy protons (Van Allen \& Frank 1959). The outer belt (at about 40,000 km from the Earth) is much larger and is surrounded by a region of low intensity mainly composed of electrons and ions, the origin of which is due to the competition of physical phenomena. Subsequent studies demonstrated that electrons with energy less than one mega electron volt occupy both zones (Johnson \& Kierein 1992), with a deep region substantially free of particles between them (Blake et al. 1997). The trapped particles are forced, by the lines of force of the geomagnetic field, to make trajectories spiraling around the Earth. Once the Earth began to cool, it was possible to form a crust of the Earth and the heavier gases began to be stationed around the Earth because the gravitational force was enough to hold them. The second atmosphere had to be very similar to the atmosphere currently present on the planets in which life did not develop such as Mars (Table 2) and composed primarily of carbon dioxide, hydrogen sulfide, ammonia, chlorine, carbon monoxide, sulfur trioxide, sulfur dioxide, and water vapor, all chemical compounds that are found today in the gases resulting from volcanic eruptions (Nuccio et al. 2014; Voigt et al. 2014). What it was definitely missed in the second atmosphere was oxygen. Today the atmosphere contains approximately $21 \%$ of free oxygen (Table 2), which corresponds to about $1.19 \times 10^{15}$ ton of oxygen (Schlesinger 1997). How was it possible to form all this oxygen? And who produced it? 
Table 2. Atmospheric composition (percent by volume) of Mars and Earth.

\begin{tabular}{ccc}
\hline Chemical compound & Mars & Earth \\
\hline Carbon Dioxide $\left(\mathrm{CO}_{2}\right)$ & 95.32 & 0.04 \\
Nitrogen $\left(\mathrm{N}_{2}\right)$ & 2.70 & 78.08 \\
Argon $(\mathrm{Ar})$ & 1.60 & 0.93 \\
Oxygen $\left(\mathrm{O}_{2}\right)$ & 0.13 & 20.95 \\
Others & 0.25 & $<20 \mathrm{ppm}$ \\
\hline
\end{tabular}

Source: https://nssdc.gsfc.nasa.gov/planetary/factsheet/marsfact.html.

\section{The Production of Oxygen on the Earth}

The production of oxygen on the Earth is mainly due to two reactions involving water and carbon dioxide (Holland 2006): photochemistry dissociation in the upper atmosphere and photosynthesis. Photochemical dissociation involves the dissociation of water molecules by the action of UV rays. This reaction, although particularly active in the stratosphere, is responsible for less than $2 \%$ of the total oxygen present on the Earth. However, with the lack of the ozone layer in the ancient Earth, a greater penetration of UV into the atmosphere could have caused a large photolysis of water. Photosynthesis is instead the process through which the carbon dioxide and water are converted into organic compounds and oxygen, which is released into the atmosphere:

$$
\mathrm{CO}_{2}+\mathrm{H}_{2} \mathrm{O}+\text { photons } \rightarrow\left[-\mathrm{CH}_{2} \mathrm{O}\right]+\mathrm{O}_{2}
$$

Photosynthesis was carried out in the past by cyanobacteria and algae, and more recently by higher plants and is the main source of oxygen in the atmosphere. There is ample evidence that it was mainly photosynthesis to produce the oxygen present in the atmosphere today (Lyons et al. 2014).

\section{The Photosynthesis as the Main Mechanism for Oxygen Formation}

There is a close correlation between the development of life and the presence of oxygen in the Earth's crust. If we analyze the composition of the Earth, and in particular its iron content, we note that iron is present in different forms. Iron is one of the elements of which the Earth is richer. In the core of the Earth iron is present in the form of molten metal while in the Earth's crust iron is rarely present in the metallic state. If we analyze the combinations of iron ores within the Earth's crust we can find the following situations: in the deeper layer called Archean (which also corresponds to the oldest period dating back about 4 billion years ago) it is possible to find layers in which iron is present in the metallic state or bound with the sulfur to form sulfides but not in the form of oxides. Continuing towards the outside of the Earth's crust it is possible to find the so called banded iron formations (BIF). These deposits, mainly marine, are characterized by structures in which it is possible to find layers of rocks alternatively rich or poor in iron. These layers contain black dark magnetite $\left(\mathrm{Fe}_{3} \mathrm{O}_{4}\right)$ that, among all 
the ores, has the highest content of iron $(\mathrm{Fe}=72.5 \%-\mathrm{O}=27.5 \%)$. These formations are dated around $2.0-2.8$ billion years ago. Continuing outwards there are the so-called red rocks. These are continental silico-clastic deposits, not older than 2.3 billion years and are attributable to the mineral hematite $\left(\mathrm{Fe}_{2} \mathrm{O}_{3}\right)$, which can be formed for further oxidation of the ferrous material. In fact, the percentage of oxygen in hematite is superior to that of the magnetite $(\mathrm{Fe}=70.0 \%$; $\mathrm{O}=$ $30.0 \%)$. The conclusion is that the amount of oxygen in the atmosphere has been increasing over almost the last 4 billion years parallel to the development of life, and this increase is seen in the composition of the Earth's crust. The oxygen produced failed to emerge in the atmosphere up to about 1 billion years ago, as the same has been absorbed by metals and other oxidizable compounds present on the Earth's crust. The amount of oxygen in the atmosphere must have accumulated over the past 500 million years and amounts to only $2.3 \%$ oxygen produced in all these years. The major part of oxygen coming from photosynthesis is chemically bound as iron oxides ( $\sim 83 \%)$ (Schaub \& Turek 2011). The global average amount of atmospheric oxygen is about $1.19 \times 10^{15}$ ton: it follows that the total amount of produced oxygen since the origin of the life is about $5.1 \times$ $10^{16}$ ton.

\section{How Much Fossil Fuel Is in the Earth?}

By considering Equation (1) it follows that: 1) one molecule of oxygen is produced from the cleavage of one molecule of carbon dioxide; 2) for each mole of oxygen present on the Earth one mole of carbon must have been produced; 3) the amount of carbon present in the Earth is proportional to the amount of oxygen produced. To calculate the amount of carbon present in the earth, a simple equation can be applied: the amount of carbon present in the earth will be equal to the moles of oxygen produced multiplied by the atomic weight of the carbon. In turn, the moles of oxygen will be equal to the weight of produced oxygen divided by the molecular weight of oxygen. The equation can therefore be written:

$$
C=O / M W\left(O_{2}\right) * A W(C)
$$

where $C$ is the amount of carbon present in the Earth, $O$ is the amount of oxygen produced since the Earth formation, $M W\left(O_{2}\right)$ is the molecular weight of oxygen (and equal to 32 atomic mass units), and $A W(C)$ is the atomic weight of carbon (and equal to 12 atomic mass units). Considering that the amount of oxygen produced during these years has been evaluated equal to be $5.1 \times 10^{16}$ ton, by replacing the abbreviations with the respective numbers we find that the quantity of carbon that must be present into the earth is about $1.9 \times 10^{16}$ ton.

\section{How Long the Fossil Fuel Era Last?}

In our day we extract approximately $1.2 \times 10^{10}$ ton of fossil fuel per year. The estimated quantities of coal and other fossil fuels can continue to support us from a point of view of energy for over a million of years! I finally came to the conclu- 
sion of my remarks: while it is true that sooner or later the fossil fuels will end up (the amount of fossil fuels stored in the Earth's crust is finite) it is also true that, continuing to burn an amount equal to that which we use today, the fossil fuels in the ground will be able to secure the energy future of mankind for several generations. We must however distinguish between reserves and resources. For energy resources means the entire oil/natural gas/coal amounts for which you know the exact location, but it is not currently possible to exploit economically or technically, as well as the sum of those amounts not yet discovered but which is assumed may lie in a specific area. Energy reserves are those quantities of oil/natural gas/coal for which we know the exact location and that are economically exploitable with current technology. The transformation of the stocks of energy resources in reserves depends both on technological progress and on the other by the price of extraction. For the sake of completeness, it is necessary to evaluate a second aspect linked to the use of fossil fuels; the decrease of oxygen in the atmosphere. The man needs oxygen to perform their vital processes. For this it is able to adapt to breathe even in situations where the amount of oxygen is greater than or less than that normally present in the atmosphere (Martin et al. 2017). If the oxygen concentration falls up 16\% there are no detectable symptoms. For oxygen concentration of about $16 \%$ an increased breathing and heart rate, an increased breathing volume, some loss of coordination, and a compromised thinking and attention can be observed. The effects are more pronounced when oxygen concentration is lower than $16 \%$. For concentrations between 14 and $16 \%$ an anomalous fatigue, stress, emotional disorder, bad coordination and altered judgment appear. Nausea, vomiting, and permanent heart damage are reported for oxygen concentration lower than $12 \%$ and finally unconsciousness followed by death for oxygen concentration lower than $10 \%$. It is undeniable that burning our fossil reserves is dramatically increasing the amount of carbon dioxide in the atmosphere, decreasing the amount of oxygen. In practice we are operating the process took place for billions of years but on the contrary. Continuing to burn coal, oil and gas we are increasing the amount of carbon dioxide in the atmosphere. At the beginning of the century the percentage of carbon dioxide was about $0.03 \%$, today is about $0.037 \%$ and it is assumed that in 2050 it will reach $0.06 \%$. Whereas to burn $1.2 \times 10^{10}$ ton of fossil fuels per year takes about $3.2 \times 10^{10}$ ton of oxygen and produces about $4.4 \times 10^{10}$ ton of carbon dioxide it follows that, in theory, a $0.5 \%$ concentration of carbon dioxide in the atmosphere will be reached in a thousand of years. Without taking into consideration the future production of oxygen by photosynthesis it is possible to calculate that we can continue to burn fossil fuels at the current rate for not more than 25,000 years when the concentration of oxygen in the atmosphere will fall down to $10 \%$. This time may seem very long for us, but geologically speaking it is a very short time (for example, modern humans have existed for 60,000 years, while our primitive ancestor lived about 4 million years ago, etc.). 


\section{Conclusion}

According to Andruleit et al. (2013) it is possible to say that in the subsoil there are still large amounts of fossil fuels. This huge potential is based on an assessment of global reserves, resources, and already consumed energy resources. It's tough to make predictions, especially in the long term, but I fear that our energy economy will be still based on fossil fuels for a large number of years. It is beyond doubt that the use of fossil fuel increases the amount of carbon dioxide and decreases that of oxygen but, also keeping constant the rate at which we are consuming fossil fuels will occur about 25,000 years before that the concentration of oxygen will fall down to worrying levels; and this without considering the continuous production of oxygen by algae, cyanobacteria and other higher plants. It is also impressive to note that, in all this time, we would have burned no more of the $2 \%-4 \%$ of the total reserves of fossil fuel present in the Earth's crust.

\section{Acknowledgements}

Part of this work was financially supported by the Italian Ministry of Economic Development through the project "Ricerca di Sistema Elettrico".

\section{Conflicts of Interest}

The authors declare no conflicts of interest regarding the publication of this paper.

\section{References}

Abas, K., Kalair, A., \& Khan, N. (2015). Review of Fossil Fuels and Future Energy Technologies. Futures, 69, 31-49. https://doi.org/10.1016/j.futures.2015.03.003

Andruleit, H., Bahr, A., Babies, H. G., Franke, D., Meßner, J., Pierau, R., Schauer, M., Schmidt, S., \& Weihmann, S. Energy Study 2013. (2013). Reserves, Resources and Availability of Energy Resources. Hannover: Bundesanstalt für Geowissenschaften und Rohstoffe (BGR).

Blake, J. B., Baker, D. N., Turner, N., Ogilvie, K. W., \& Lepping, R. P. (1997). Correlation of Changes in the Outer-Zone Relativistic Electron Population with Upstream Solar wind and Magnetic Field Measurements. Geophysical Research Letters, 24, 927-929. https://doi.org/10.1029/97GL00859

Holland, H. D. (2006). The Oxygenation of the Atmosphere and Oceans. Philosophical Transactions of the Royal Society B: Biological Sciences, 361, 903-915. https://doi.org/10.1098/rstb.2006.1838

Johnson, M. H., \& Kierein, J. (1992). Combined Release and Radiation Effects Satellite (CRRES), Spacecraft and Mission. Journal of Spacecraft and Rockets, 29, 556-563. https://doi.org/10.2514/3.55641

Lyons, T. W., Reinhard, C. T., \& Planavsky, N. J. (2014). The Rise of Oxygen in Earth's Early Ocean and Atmosphere. Nature, 506, 307-315.

https://doi.org/10.1038/nature13068

Martin, D., McKenna, H., \& Livina, V. (2017). The Human Physiological Impact of Global Deoxygenation. The Journal of Physiological Sciences, 67, 97-106. 
https://doi.org/10.1007/s12576-016-0501-0

Nuccio, P. M., Caracausi, A., \& Costa, M. (2014). Mantle-Derived Fluids Discharged at the Bradanic Foredeep/Apulian Foreland Boundary: The Maschito Geothermal Gas Emissions (Southern Italy). Marine and Petroleum Geology, 55, 309-314. https://doi.org/10.1016/j.marpetgeo.2014.02.009

Schaub, G., \& Turek, T. (2011). Energy Flows, Material Cycles and Global Development. Berlin Heidelberg: Springer-Verlag. https://doi.org/10.1007/978-3-642-12736-6

Schlesinger, W. H. (1977). Biogeochemistry: An Analysis of Global Change (2 ${ }^{\text {nd }}$ edn). San Diego: Academic Press.

Sterman, J. D., \& Richardson, G. P. (1985). An Experiment to Evaluate Methods for Estimating Fossil Fuel Resources. Journal of Forecasting, 4, 197-226. https://doi.org/10.1002/for.3980040208

Van Allen, J. A., \& Frank, L. A. (1959). Radiation around the Earth to a Radial Distance of 107,400 km. Nature, 183, 430-434. https://doi.org/10.1038/183430a0

Van Allen, J. A., Ludwig, G. H., Ray, E. C., \& McIlwain, C. E. (1958). Observation of High Intensity Radiation by Satellites 1958 Alpha and Gamma. Journal of Jet Propulsion, 28, 588-592. https://doi.org/10.2514/8.7396

Voigt, C., Jessberger, P., Jurkat, T., Kaufmann, S., Baumann, R., Schlager, H., Bobrowski, N., Giuffrida, G., \& Salerno, G. (2014). Evolution of $\mathrm{CO}_{2}, \mathrm{SO}_{2}, \mathrm{HCl}$, and $\mathrm{HNO}_{3}$ in the Volcanic Plumes from Etna. Geophysical Research Letters, 41, 2196-2203. https://doi.org/10.1002/2013GL058974

Yang, X., Gaillard, F., \& Scaillet, B. (2014). A Relatively Reduced Hadean Continental Crust and Implications for the Early Atmosphere and Crustal Rheology. Earth and Planetary Science Letters, 393, 210-219. https://doi.org/10.1016/j.epsl.2014.02.056 